\title{
Evidence-Based Practice: Community-Based Palliative Cancer Care
}

\author{
${ }^{1}$ Jajang Ganjar Waluya, Nur Maziyya, ${ }^{2}$ Eva Nurlaela, ${ }^{2}$ Ita Vusfita,,${ }^{2}$ Ihda Al Adawiyah Mz, \\ ${ }^{2}$ Kusman Ibrahim, ${ }^{2}$ Ikeu Nurhidayah, ${ }^{2}$ Laili Rahayuwati \\ ${ }^{1}$ Puskesmas DTP Cipanas, ${ }^{2}$ Faculty of Nursing, Universitas Padjadjaran \\ Email: laili.rahayuwati@unpad.ac.id
}

\begin{abstract}
Prevalence of cancer is estimated will increase in the next two decades. Therefore, there is a challenge for health provider to encounter treatment and caring for the patients. Especially, the cancer patients face several problems not only physical but also psychological, emotional, spiritual and social cultural aspects. This study explored the evidence-based practice on community-based palliative cancer care. Literature study is done by making a summary of published articles related to the question. The searching method used several electronic databases such as Google Scholar, Proquest, and PubMed. Articles under the keywords of "Palliative Cancer Care", "Community", and "Nursing" reach as much as 1.804. The inclusion criteria for this literature review were articles that have been peer-reviewed, are in full-text, in either English or Indonesian, and publication year from 2008 to 2018. Meanwhile, the exclusion criteria include those that do not follow a standardized structure of an article (consisting of Abstract, Introduction, Method, Result, Discussion, Implication, and Reference), are in the form of a review, and whose content does not answer research questions. The United States of America is on the highest place regarding palliative care service, following by community-based palliative cancer implementation in Europe. Asian countries had been applying palliative care service, integrated with national health care system. In the Middle East countries, palliative care program ranks the lowest, but in implementation, they have discreetly performed community-based palliative care. In Africa, it is not the main focus in the field of health. Palliative care for cancer patients that is potential for development in Indonesia is that of family-based. Community-based palliative care is a variant of palliative treatment long applied and being developed in many countries in the world. In continents such as America and Europe, the implementation of palliative care ranks the highest place. In Indonesia, it is done partially and only available in hospitals or non-governmental organization. In the level of community, family-based palliative care can be developed by involving trained family members.
\end{abstract}

Keywords: Cancer, evidence-based practice, palliative care. 


\section{Introduction}

Cancer is one of the main death causes in the world, around $60 \%$ new cases and $70 \%$ death due to cancer worldwide occurs in Africa, Asia, and Central and South America. It is estimated that annual cancer cases will increase from 14 million in 2012 to 22 million in the next two decades. Nationwide, the prevalence of cancer to Indonesians in 2013 is $1.4 \%$ or around 347.792 people. Cervix and breast cancer are those among the highest prevalence in Indonesia in 2013. The former reaches as much as $0.8 \%$ while the latter $0.5 \%$.

Cancer may cause indications and symptoms for the patients, and some treatments are available for this. Advanced stage cancer patients encounter many problems. The physical symptoms may cause suffering and have the potential to affect emotion, social life, and spirituality for both the patient and her family as well as relatives (Higginson and Evans 2010).

One of the objectives of cancer treatment is to reduce the symptoms and effects from exactly that. It is to provide comfort and improve the life quality of the patient from the first diagnosis to the end of her life. The treatment is called palliative care, which according to $\mathrm{WHO}$ is an integrated service by palliative team to improve the life quality of the patient and provide support for the family facing problems related to the patient's condition. This is done by preventing and reducing suffering through early identification, holistic assessment, and treatment for pain and other complications, including those of physical, psychosocial, and spiritual.

Palliative care is an effective approach for the patient whose illness is not curable to reduce suffering and improve her and her family life quality. This is to anticipate potential problems and minimize impacts from the illness progressivity, so that the patient can optimize her body to function before she dies.

Indonesia is now facing a challenge of the increasing number of non-infectious disease incidents such as cancer. As the consequence, the number of patients requiring palliative service is also getting up. Generally, palliative care is a service provided to patients whose illness is no longer reactive to curative or medical treatment before the final stadium (Utari, 2008). The biggest concern for palliative cancer occurs in HIV/AIDS cancer. In Indonesia, palliative care service started in 1990 through the establishment of exemplary palliative care in the then existing health institutions (Al-Shahri, 2002; Soebadi \& Tejawinata, 1996). The global picture of Indonesian palliative care is currently classified as a $3 \mathrm{a}$ level-that is, it is not wholly integrated into the main health care service (Lynch et al., 2013).

Passing away in a meaningful and dignified condition is the objective of palliative care. For advanced stadium patients, whose cancer is no longer curable, palliative care is required to maintain her spirit to survive and hence improve her life quality. As a matter of fact, it is not only about taking care of patients with imminent death, but it is also about how the nurses can accompany and guide the patient to live her life fully despite the chronic illness.

This has sparked a question on how the community-based cancer palliative care is implemented to cancer patients worldwide, how it is implemented in Indonesia, who are authorized to do it, what are the regulations, what kinds of obstacles and supporting factors in giving the service in Indonesia, and what is the role of the nurses in cancer palliative care in Indonesia.

The aim of this paper is to respond to these questions through literature review pertaining to community-based cancer palliative care in developed and developing countries, specifically Indonesia. Its goal is to identify the provision of palliative service and the obstacles and supporting factors that may emerge along the way. This is to share a common understanding where health professionals, including nurses, can contribute to the improvement of conditions and qualities of cancer palliative care in Indonesia.

\section{Research Method}

The literature review was done through resumes of published articles relevant to the 
Jajang Ganjar Waluya: Evidance-Based Practice: Community-Based Palliative Cancer Care

questions above. The searching method used several electronic databases such as Google Scholar, Proquest, and PubMed. Articles under the keywords of "Palliative Cancer Care", "Community", and "Nursing" reach as much as 1.804 . The inclusion criteria for this literature review were articles that have been peer-reviewed, are in full-text, in either English or Indonesian, and publication year from 2008 to 2018. Meanwhile, the exclusion criteria include those that do not follow a standardized structure of an article (consisting of Abstract, Introduction, Method, Result, Discussion, Implication, and Reference), are in the form of a review, and whose content does not answer research questions.

\section{Research Results}

\section{a. Palliative Cancer Care in America and Europe, America}

The United States of America is on the highest place regarding palliative care service - that is, under the category $4 \mathrm{~b}$ (Walker, Edwards, Bagcivan, \& Bakitas, 2017). This goes hand in hand with an article by Reville \& Foxwell (2014) saying that America, Australia, and few European countries place the highest category (4b) in palliative care service. The categorization is assessed based on some factors according to the World Palliative Care Association (WPCA), including a model of palliative care provision, access for pain relief medication (morphine), level of consciousness and activity of health care provider and policy in the society, and the centre of education and occupation association. A 4b country means that it has a comprehensive and progressive integrated hospice-palliative care service (Reville \& Foxwell, 2014).

The United States of America has all the components in such assessment, including an advanced integrity for several nursing locations, the provision of comprehensive palliative service, the awareness and extensive knowledge of the people and healthcare staff regarding palliative care, limitless opioid access, policy and education on palliative care as well as national palliative nurses association (Walker et al., 2017). However, the one in the U.S. is not universally integrated to hospitals and communities; there are obstacles for palliative care access there (Walker, Edwards, Bagcivan, \& Bakitas, 2017).

The obstacle faced during the implementation of palliative care in a developed country such as the U.S. is the inadequacy of information received by patients regarding palliative care, its impacts to their health, and the cost of cancer treatment that may cause misunderstanding regarding that of palliative care (IOM, 2013).). Other challenges include lack of knowledge of referral doctors and families regarding the benefits of palliative care (CAPC, 2011; Kirch \& Brawley, 2012), irregular reports from referral cancer patients to palliative care specialists (Bruara \& Hui, 2010), and amateur oncology doctor when it comes to handling communication handicaps that might occur (Abraham, 2012).

Community-based palliative care in America has many forms of interventions, one of which is Nurse Navigators and Psychoeducation Program. This is linear with a research by Dockham et al., (2016) in America regarding the implementation of the program to 34 couples of cancer survivors, together with their families. The result of the research shows an increase of their life quality (physical, emotional, and functional aspects included). Meanwhile, regarding Nurse Navigators, a research by Wagner et al., (2014) in America to 251 new cancer patients (intervention $\mathrm{n}=133$ and control $\mathrm{n}=18$ ) shows obedience (problem reduction) during the treatment, but it does not show increase in life quality.

A research from Mazanec and Prince-Paul (2014) in the United States find that many cancer centres and clinics claim that they have palliative care service. However, the structure, process, and result of the program is highly diverse. Some of them admit to have a counselling model, but most programs are limited to only in-patient service, and even lesser out-patient counselling service programs.

Community-based palliative cancer implementation in Europe occurs in Ireland. The intervention done by Dignity Care Intervention Program is an empirical model from the evidence-based result and research 
with the objective that community nurses can identify the patient's needs, provide holistic treatment focusing on the patient, and safeguard the patient's dignity while it lasts. From a survey-based evaluation result and focus group discussion to nurses implementing DCI, it shows that community nurses get benefits from this program. It becomes the facility for them to provide holistic treatment for cancer patients and accompany them to die with decency (Mclfatrick et al., 2017).

\section{b. Palliative Cancer Care in Asia}

Most of cancer patients in Asian countries are in the final stadium, in which curative implementation is no longer applicable. In other words, they experience suffering, other relevant symptoms, and psychosocial complications. In an Asian country with high GDP such as Japan, Hong Kong, and Singapore, oncology service can be paired with that in developed countries. However, in countries with lower GDP such as Burma, Laos, and Cambodia, many cancer patients do not even get a basic cancer treatment. In these countries, supportive, palliative, and pre-demise treatment for cancer patients with low economic status, are paramount. The three treatments have the potential to improve the life quality, control pain, reduce the suffering of the patient and her family, and accompany patients to die with decency.

The reports from the Worldwide Palliative Care, together with the International Observatory on End of Life Care, claims that in Asia, countries whose palliative care activities are yet to be revealed are Afghanistan, Bhutan, North Korea, Laos, and Pacific Island. Meanwhile, Asian countries applying palliative care service, integrated with national health care system, are Hong Kong, Japan, and Taiwan. Furthermore, those countries struggling with the implementation of the service includes Indonesia, Philippine, Thailand, and India. And those whojust started include China, Malaysia, and Mongolia.

Hong Kong and Taiwan are two Asian countries that have implemented palliative care effectively, integrated with a national healthcare provider, and covered all cancer patients. These two countries are rapidly developing in terms of economy, with most areas are cities. For countries with broad area, the coverage of the service is a challenge on its own. Although the patients gather in Hospital and Cancer Centre in big cities for cancer therapy, the support for them once returned home requires basic skill of palliative care for healthcare staff in remote areas. Besides, the staff need to have a training about the use of opiate anti-pain medication.

The type of palliative care program developed in Asia is the involvement of volunteers from neighbouring countries or people within the circle of cancer patients. Neighborhood Network in Palliative Care (NNPC) is one of the endeavours done by Kerala, established in 2001. It applies the principle that communities (surrounding people) called volunteers have the obligation to take care of and look for the sick. It mushrooms with more than 2500 patients every week, and volunteers act as its soul. They are trained to provide emotional support and basic treatment for the patients. They are also the mediator between healthcare staff, in this case nurses, and the patients (Abraham \& Jithesh, 2012).

The education of professional palliative care workers is partially distributed in Asia. Most of these workers, willing to be trained in the field of palliative care, had to enrol a course in another institution. This is because higher learning institutions providing formal education of palliative care are limited in number. In countries such as Singapore, Taiwan, Hong Kong, Japan, South Korea, India, and Thailand, a structured training program has been developed for both doctors and nurses.

Most professional healthcare workers in Asia are accustomed to the Western education model; therefore, when it comes to developing palliative care education curriculum on their own, they need to refer fully to that in Western countries. As a matter of fact, palliative care education is way better to implement using national language than using learning methods such as lecture, role play, watching videos or films, and using case studies to improve understanding about palliative care.

In Singapore, nursing and health students receive palliative care education. For instance, during freshman year, they will endure a pre- 
demise nursing training for $2-4$ hours, and palliative care under the subject of oncology sophomore year. Students taking advanced diploma or specializing in palliative care will endure additional course on palliative care.

International Association for Hospice and Palliative Care (IAHPC) has made a list of essential palliative care in three major components, namely identifying and managing the physical, psychological, and spiritual needs of the patient and her family. Treatment planning and coordination and communication issues (Payne et al., 2012).

\section{c. Palliative Cancer Care in the Middle East}

In the Middle East countries (Jordan, Lebanon, Cyprus, Turkey, Palestine, Israel) palliative care is mostly taken over by non-governmental sectors. This is because the country, NGOs, healthcare staff, and volunteers, have come to deal for collaboration (Silbermann et al., 2012). This is strengthened by Walker et al., (2017), saying that in Turkey, the health insurance covers all check-up costs, from screening to cancer treatment. The implementation of community-based palliative cancer in the Middle East countries has been done even before it becomes a trend due to a robust relationship established in the family. If a family member faces difficulty in any form, then the rest of the family will come to help. Therefore, in practice, the family can function as a unit of home palliative care (Silbermann et al., 2012). Walker (2017) shows similar view regarding palliative care in Turkey.

In Turkey, palliative care is the weakest program of all. This is because they uphold traditional family structure, in which all members of a family will come to help when one is in such difficult place. This has become an intrinsic palliative tendency but does not reflect in the eyes of professional healthcare staff system (Walker et al., 2017).

\section{d. Palliative Cancer Care in Africa}

Cancer palliative care in African regions has not yet become the main focus for both the people and the government. This is linear with the argument of Walker, Edwards, Bagcivan, \& Bakitas (2017). They find Malawi government (African sub-Saharan region) has not put much thought into cancerrelated issues, quite as opposed to infectious disease such as HIV/AIDS. Therefore, patients requiring cancer palliative care will have to endure the treatment for HIV/AIDS. Busolo and Woodgate (2016) elaborate that seldom have any research, education, and policy on palliative care been done or endeavoured in Africa. Another result shows lack of awareness on palliative service and inadequate and undistributed resources. Similarly, the research suggests that cancer patients requiring palliative care experience minimum treatment in all nursing domains.

\section{e. Palliative Cancer Care in Indonesia}

A research by Rochmawati, Wiechula, Cameron (2016) identify that the development of cancer palliative care in Indonesia is limited and slow-moving due to multiple factors. The most reported challenge is the healthcare staff's lack of knowledge on palliative care. Besides, the inadequate facilities and support from family and the people. Palliative care in Indonesia is provided by the hospital and nongovernmental organization. The information of the service is passed down to people from all ages, with one specific organization focusing on the pediatric palliative care provision (Effendy et al., 2015). This organization provides management of symptoms, spiritual and emotional treatment as well as support for the patient and her family in nursing houses and home-based treatment program. Models relevant to the service including that of hospital-based, home-based, and community-based.

\section{Discussion}

All patients have the right to get access to that treatment. In developed countries, palliative care has been integrated to oncology service, while in developed ones it remains the main focus due to its inadequate service facilities. Twenty years ago, WHO developed an integration of public health and palliative care into the then existing health service system. This recommendation requires every country to have national cancer control program, in which palliative service is provided. The benefit of palliative care with public health 
Jajang Ganjar Waluya: Evidance-Based Practice: Community-Based Palliative Cancer Care

approach is that the people become more aware and sensitive of the local condition and issues, and to get to know evidence-based intervention with relatively affordable price.

Palliative care for cancer patients that is potential for development in Indonesia is that of family-based. A research by Kristianti et al., (2017) shows that family-based palliative care on cancer patients show significant change in the status of general health, emotion, social function, pain, fatigue, respiratory issues, insomnia, decreasing appetite, constipation, and financial crisis. The intervention given was training for the family of cancer patients, including basic treatment skill such as bathing, shampooing, assisting elimination aid, oral and dental treatment, as well as feeding in bed.

\section{Conclusion}

Palliative care is an effort that focuses on the improvement of life quality and reduction of discomfort due to pain from terminal illness. Community-based palliative care is a variant of palliative treatment long applied and being developed in many countries in the world. In continents such as America and Europe, the implementation of palliative care ranks the highest place, but there are some problems on community-based palliative care. Meanwhile, in the Middle East countries, palliative care program ranks the lowest, but in implementation, they have discreetly performed community-based palliative care. In Africa, it is not the main focus in the field of health. In Indonesia, it is done partially and only available in hospitals or non-governmental organization. In the level of community, family-based palliative care can be developed by involving trained family members.

Sustainable education and research on palliative care for cancer patients in communities must be developed especially in countries such as Indonesia. Besides, an integration between Public Health and Oncology Service in palliative care requires national health system support.

\section{References}

Abrahm, J. L. (2012). Integrating palliative care into comprehensive cancer care. Journal of the National Comprehensive Cancer Network, 10(10), 1192-1198.

Bruera, E., \& Hui, D. (2010). Integrating supportive and palliative care in the trajectory of cancer: Establishing goals and models of care. Journal of Clinical Oncology, 28(25), 4013-4017. http://dx.doi.org/10.1200/ JCO.2010.29.5618

Center to Advance Palliative Care (CAPC). (2011). Public opinion research on palliative care: A report based on research by public opinion strategies. Retrieved from http:// www.capc.org/tools-for-palliative-careprograms/marketing/public-opinionresearch/2011-publicopinion-research-onpalliative-care.pdf.

Dockham, B., Schafenacker, A., Yoon, H., Ronis, D. L., Kershaw, T., Titler, M., \& Northouse, L. (2016). Implementation of a psychoeducational program for cancer survivors and family caregivers at a cancer support community affiliate: A pilot effectiveness study. Cancer Nursing, 39(3), 169-180. https://doi.org/10.1097/ NCC.0000000000000311.

Institute of Medicine (IOM). (2013). Delivering high-quality cancer care: Charting a new course for a system in crisis. Washington, DC: The National Academies Press.

Kim, S. N., Choi, S. O., Shin, S. H., Ryu, J. S., \& Baik, J. W. (2017). Development of a community-based palliative care model for advance cancer patients in public health centers in Busan, Korea. Cancer Research and Treatment, 49(3), 559-568. https://doi. org/10.4143/crt.2016.276.

Kirch, R. A., \& Brawley, O. (2012). Palliative care: A lifeline to quality of life. Journal of Oncology Practice, 8(2), 128-129. http:// dx.doi.org/10.1200/JOP.2011.000530. 
Jajang Ganjar Waluya: Evidance-Based Practice: Community-Based Palliative Cancer Care

Kristanti, M. S., Setiyarini, S., \& Effendy, C. (2017). Enhancing the quality of life for palliative care cancer patients in Indonesia through family caregivers: A pilot study of basic skills training. BMC Palliative Care, 16(1), 1-7. https://doi.org/10.1186/s12904016-0178-4.

Reville, B., \& Foxwell, A. M. (2014). The global state of palliative care-progress and challenges in cancer care. Annals of Palliative Medicine, 3(3), 129-138. https://doi. org/10.3978/j.issn.2224-5820.2014.07.03.

Silbermann, M., Arnaout, M., Daher, M., Nestoros, S., Pitsillides, B., Charalambous, H., ... Oberman, A. (2012). Palliative cancer care in middle eastern countries:
Accomplishments and challenges. Annals of Oncology, 23(SUPPL.3), 15-28. https://doi. org/10.1093/annonc/mds084.

Wagner, E. H., Ludman, E. J., Aiello Bowles, E. J., Penfold, R., Reid, R. J., Rutter, C. M., ... McCorkle, R. (2014). Nurse navigators in early cancer care: A randomized, controlled trial. Journal of Clinical Oncology, 32(1), 12-18. https://doi.org/10.1200/ JCO.2013.51.7359.

Walker, D. K., Edwards, R. L., Bagcivan, G., \& Bakitas, M. A. (2017). Cancer and Palliative Care in the United States, Turkey, and Malawi: Developing Global Collaborations. Asia Pac J Oncol Nurs, 4(3), 127-135. https://doi. org/10.4103/apjon.apjon. 